пСихология

DOI: $10.17805 /$ trudy.2019.4.1

\title{
ЗАРОЖДЕНИЕ ПОНЯТИЙ «ВНУТРЕННИЙ ЧЕЛОВЕК» И «СУБЪЕКТИВНОЕ ВРЕМЯ» В ПОЗДНЕЙ АНТИЧНОСТИ
}

\begin{abstract}
Д. В. Сочивко
Академия права и управления Федеральной службы исполнения наказаний, 2. Рязань

Аннотация: В статье рассмотрены концепции внутреннего человека и субъективного психологического времени, как они зарождались в античной и раннехристианской философии. Показана роль этих понятий для современной психологии, в особенности православной психологии и психотерапии.
\end{abstract}

Ключевые слова: внутренний человек; субъективное время; Античность; поздняя Античность; история психологии; история христианства

\section{ORIGIN OF THE CONCEPTS “INNER MAN" AND “SUBJECTIVE TIME” IN LATE ANTIQUITY}

\author{
D. V. Sochivko \\ Academy of Law and Management, Federal Penitentiary Service
}

\begin{abstract}
The paper considers the concepts of the inner man and subjective psychological time as they originated in ancient and early Christian philosophy. The author demonstrates the role of these concepts for modern psychology, Orthodox Christian psychology and psychotherapy in particular.
\end{abstract}

Keywords: inner man; subjective time; antiquity; late antiquity; history of psychology; history of Christianity

Период зарождения средневековой философии охватывает и первые века христианства, таким образом, в существенный мере пересекается с периодом поздней античности.

Собственно зарождение средневековой философии относится многими авторами ко II-V вв. При этом, куда отнести первый век, как бы оставленный в античности, понять трудно. На наш взгляд, первый век после Р. Х., который можно было бы назвать апостольским веком в истории философии и психологии, несмотря на господство язычества, отличается тем, что именно в это время заканчивается формирование концепции внутреннего человека, начатое еще стоиками и неоплатониками, которая станет неявным ядром антропологии и психологии во все последующие века и до наших дней. 
«Неявным» потому, что редко специально подчеркивается авторами, но легко доказать, что, как это делалось многими философами и психологами во все века после Р. Х., является основой методологических и теоретических установок научных исследований «человека разумного».

Сам термин внутренний человек впервые употреблен апостолам Павлом в его втором письме к Коринфянам «Посему мы и не унываем, но если внешний наш человек и тлеет, то внутренний со дня на день обновляemcя» $(2$ Кор. 4,16$)$. Сопоставление «уныния», как одного из самых страшных грехов в христианстве, являющегося прямым следствием гордыни, с «тлением внешнего человека» определяет принципиально новую психологическую парадигму взгляда на психику человека в целом. Становятся явными самые глобальные психодинамические полюса в интрапсихической структуре личности и поведения человека. Согласно современным представлениям, о чем нам неоднократно приходилось писать, психодинамические полюса - это центры психических сил, между которыми напряжено некоторое силовое поле. В этом поле существует огромное множество сочетаний психодинамических типов. Психоэнергетическим полюсом выступает любое свойство психики, со своим зарядом и на своем месте в общей психоэнергетике и психодинамике (Сочивко, 2007). Мы сейчас говорили о главных полюсах психодинамической напряженности - внутреннем и внешнем человеке. Внешний тлеющий человек, погруженный во внешний мир, который пленяет его физическим пространством-временем, сетью страстей, желаний и последующих болезней и внутренний человек, обретший свободу в своем настоящем бытии. Говоря о «настоящем» бытии, мы имеем ввиду настоящее субъективного (см. ниже) психологического и исторического времени бытия внутреннего человека (см. рис. 1).

Апостол Павел так пишет об этом «потому, что вы слушали о Нем и в Нем научились, — так как истина во Иисусе, 一 отложить прежний образ жизни ветхого человека, истлевающего в обольстительных похотях, а обновиться духом ума вашего и облечься в нового человека, созданного по Богу, в праведности и святости истины» (Еф. 4, 22-24).

Новый человек в этих словах Павловых и есть человек внутренний.

Итак, обновлению во внутреннего человека мы научились у Иисуса. Иисус же, по его собственным словам, и есть «путь и истина» («Я есмь путь и истина»). Таким образом, весь наш жизненный путь, если строить его по истине, заложен во внутреннем человеке, а внешний человек может только приостановить свое тление, энергетически подпитываясь от человека внутреннего. Но это только в идеале.

Отсюда становится понятным религиозный смысл слов св. Василия Великого (IV в. после Р. X.) «Вонми себе и вонмиши Богу». Святитель обраща- 
Научные труды Московского гуманитарного университета 2019 № 4

ется не к внешнему человеку, не к пожеланиям и похотениям нашим, которым мы итак готовы всегда внимать, но к внутреннему человеку, носителю истины.

Такая парадигма психодинамики внутреннего и внешнего человека, установившаяся со времен бытия на земле самого Христа, принципиально противоположна античной языческой установке. Здесь во всем правит внешний человек. Именно это имел в виду А. Ф. Лосев (Лосев, 1993), говоря о принципиальной фатальности античной философии и психологии, где человек раб своей судьбы, обстоятельств и страстей, несмотря на то, что он человек разумный.

Вторым базовым моментом, который также прослеживается еще у древних и окончательно формируется в концепцию принципиального отличия человека внешнего от человека внутреннего - это концепция психологического субъективного времени внутреннего человека, в котором он живет, в отличии от человека внешнего, который живет большей частью в обычном физическом времени и пространстве. По словам Плотина: «Наконец, если я осмелюсь, в противоположность мнению всех прочих людей, высказать свободно и определенно свое собственное убеждение, то, по-моему, в чувственном теле пребывает постоянно не вся наша душа, а только некоторая ее часть, которая, будучи погружена в этот мир и потому уплотняясь или, лучше сказать, засоряясь и омрачаясь, препятствует нам воспринимать то, что воспринимает высшая часть нашей души».

В другом месте он говорит: «Души подобны амфибиям: они живут то по сю сторону, то в потустороннем мире, смотря по надобности». В наших терминах то в физическом, то в субъективном пространстве времени.

Физическое время линейно, непрерывно и плотно (cм. puc. 1).

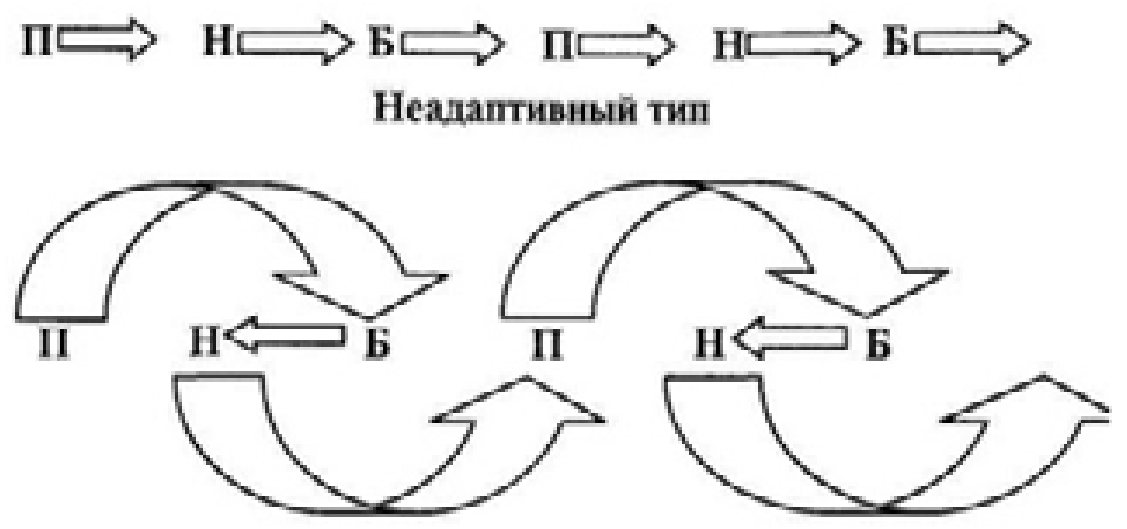

Рис. 1. Спиралевидная структура психического времени адаптивного субстанционального деятеля (психоида) в сравнении с неадаптивным. 
За прошлым следует настоящее, за ним будущее. Как говорил св. Василий Великий, прошлое уже ушло, будущее не наступило, а настоящее исчезающе мало.

Субъективное психологическое (историческое) время нелинейно, спиралевидно, и необходимо разрывно, причем именно в точке настоящего. Сходство особенностей психологического и исторического времени имеет свое значение (если, например, грубо рассматривать историю, как огромный поток психических явлений).

В физике мы исследуем именно связь прошлого и будущего, и поэтому делаем акцент на том, например, что камень, брошенный с башни, обялзательно будет падать непрерывно, пока не коснется земли. При этом для нас абсолютно безразличен тот факт, что тот же самый камень затем опять будет поднят на башню. А возможно и погрузится в историческое настоящее, не имеющее длительности, став музейным экспонатом.

Таким образом, в истории же для нас, напротив, важна судьба именно этого камня в его настоящем, которое повторится со вторым бросанием, пока не будет окончен эксперимент.

Поэтому исторические (психологические) события могут пре-рываться, т. е. то, что началось давно, может не длиться теперь, потом вновь начать длиться. Для физической длительности это невозможно.

Моцарт как-то сказал, что высшие формы вдохновения он ощущает, когда видит свою симфонию, как яблоко на руке, т. е. единовременно. А это боле 30-40 минут физического времени.

В результате мы намерены утверждать, что именно субъективное психологическое время есть время внутреннего человека, а физическое время - время внешнего. С общепсихологической точки зрения человек, полностью погруженный в физическое время не адаптивен, он как бы течет по течению, натыкаясь на все соблазны и препятствия страстей и уныния. Сейчас мы попробуем это показать.

Если изложенные выше положения о структуре психологического времени верны, то основные компоненты психики должны быть как-то ориентированы в этом времени. Под основными компонентами мы имеем в виду издревле известную психологическую триаду - эмоции, познание и воля.

Эмоции (как переживания) связаны с психологическим прошлым, воля (с ее акцептором будущего) - с будущим, познание находится в настоящем, причем именно в психологическом настоящем.

Итак, сопоставим эмоции (Э) = прошлое (П), воля (В) = будущее (Б) и познание $(\Pi)=$ настоящее $(\mathrm{H})$. Всего имеется только две (комбинаторных) возможности разных последовательностей включения волевых, эмоциональных и когнитивных процессов. Первый вариант - последователь- 
ность $(Э П В)=($ ВЭП $)=(\text { ПВЭ })^{1}$. Равенство здесь означает, что циклическая смена может начаться с любого компонента, но всегда Э переходит в П, П в В, а В снова в Э, затем цикл повторяется.

Второй вариант $-(Э В П)=($ ВПЭ) $=($ ПЭВ $)$. Других вариантов не существует. Разница этих двух последовательностей заключается, в первую очередь, в моменте включения когнитивного фактора (П).

Для неадаптивного типа эмоции непосредственно запускают определенный познавательный процесс (ЭПВ), тем самым, овладевая им и всей личностью, т. к. именно познание является сущностным свойством человека разумного (см. рис. 1).

Очищение познания от страстей (эмоций) известно многим мировым религиям как практика духовного развития. Так у православных святых отцев с первых веков христианства можно найти подробно описанную поэтапную динамику впадания человека в грех и утраты внутреннего человека (См. например, Авва Дорофей - Душеспасительные поучения). Первый этап - возникновение эмоции-страсти, поначалу не сильной, движения души к соблазну. Второй этап - сосложение - присоединение ума (когниции). На этом этапе соблазнительный образ запретного (греховного). Далее возможны два пути: либо человек после благорассмотрительного рассуждения (познания) откажется действовать по страсти и сохранит структуру субъективного времени, либо позволит страсти овладеть волею, игнорируя познание, и «облекаясь» вновь во внешнего человека. Такое включение волевого компонента и дает нам адаптивный, с точки зрения общей психологии, ибо она еще не знает внутреннего человека, психодинамический тип личности (ЭВП).

Но если вернуться к рисунку 1, то мы видим, что своевременное включение волевого компонента и делает возможным переход прошлого в будущее, а затем только в настоящее, в котором и вершиться акт действования.

Установив связь субъективного времени с внутренним человеком, сосредоточимся на том, как эта концепция сформировалась еще в поздней античности и, делая скачок из прошлого в будущее, оценим роль первых христиан для современной психологии.

Впервые в античности проблему времени остро поставил Зенон Элейский, известный своими апориями, отрицающими факт существования движения.

Современники упоминали 40 апорий Зенона, до нас дошли 9, обсуждаемые у Аристотеля и его комментаторов. Наиболее известны апории о движении:

\footnotetext{
${ }^{1}$ Круглые скобки означают циклическое движение трех компонентов.
} 
- Ахиллес и черепаха,

-Дихотомия,

- Стрела,

- Стадион.

Для нас особый интерес представляют апории о движении, которые раскрывают понятие древних о психодинамике субъективного времени. Перейдем к описанию самих апорий в их античном и современном психодинамическом понимании.

Быстроногий Ахиллес никогда не догонит неторопливую черепаху, если в начале движения черепаха находится впереди Ахиллеса.

Допустим, Ахиллес бежит в десять раз быстрее, чем черепаха, и находится позади неё на расстоянии в тысячу шагов. За то время, за которое Ахиллес пробежит это расстояние, черепаха в ту же сторону проползёт сто шагов. Когда Ахиллес пробежит сто шагов, черепаха проползёт ещё десять шагов, и так далее. Процесс будет продолжаться до бесконечности, Ахиллес так никогда и не догонит черепаху.

Диоген Лаэртский считал автором этой знаменитой апории Парменида, учителя Зенона.

Скрытым психодинамическим смыслом этой апории является то, что Ахиллес не догонит черепаху не в абстрактном или физическом времени, а именно в субъективном времени. В физическом времени Ахиллес, конечно же, черепаху догонит. В субъективном же времени отсутствует совпадение будущего. Когда Ахиллес догнал черепаху, для него наступает будущее субъективное время. Для черепахи, которая не успела еще сделать ни шагу, будущее время наступает физически позднее. Именно внутри этой временной задержки Ахиллес и обгоняет черепаху физически, что, однако, никак не учитывается в физическом времени. Если сравнить положение Ахиллеса и черепахи в субъективном времени, не имеющим длительности, то топологически они будут оставаться на своих местах, хотя и будут осуществлять движения конечностями. В субъективном настоящем мы по прежнему будем иметь Ахиллеса и черепаху, если только кто-то из них не исчезнет из этого настоящего и наступит другое настоящее, новый цикл субъективного времени. Проще говоря, забег Ахиллеса и черепахи просто закончится. Также как заканчивается симфония Моцарта, оставаясь тем же единым «яблоком на руке» в творческом настоящем композитора. Аналогичный анализ можно провести и по другим апориям.

Таким образом, Зенон прав в том, что в структуре субъективного настоящего времени действительно нет движения. И в этом в частности сказывается и богоподобие человека Богу. Зачем Богу движение, если он обладает вездеприсутствием. 
Научные труды Московского гуманитарного университета 2019 № 4

Человек же скован физическим пространством и временем «здесь и теперь» (образ вечности, учитывая, что настоящее не имеет длительности), вездеприсутствием не обладает, но свободен во времени субъективном настоящем времени внутреннего человека.

Этим свойством в настоящее время научились пользоваться психотерапевты, заставляя клиента сосредоточиться «здесь и теперь», что позволяет хоть как-то подобраться к внутреннему человеку.

Эту же технику «здесь и теперь» необходимо использовать как основной прием и в еще только нарождающейся православной психотерапии, которая, как и всякая психотерапия, направлена на изменения внутреннего человека. В православной терапии мы полагаем, что эта глубокая психологическая перемена происходит в нас под действием благодати Божией: Да даст вам, по богатству славы Своей, крепко утвердиться Духом Его во внутреннем человеке $(\mathrm{E} \phi .3,16)$.

Тогда происходит распятие со Христом нашего ветхого внешнего человека, чтобы упразднено было тело греховное, дабы нам не быть уже рабами греху (Рим. 6, 6), и восстает сокровенный сердца человек в нетленной (красоте) кроткого и молчаливого духа (1 Пет. 3,4).

Тогда мы становимся даже причастниками Божественного естества по слову апостола Петра (2 Пет. 1, 4), верою вселиться Христу в сердца наши, чтобы мы, укорененные и утвержденные в любви, могли постигнуть со всеми святыми, что широта и долгота, и глубина и высота, и уразуметь превосходящую разумение любовь Христову, дабы нам исполниться всею полнотою Божиею (Е

И наконец, итог православной психотерапии, указывающей и субъективное время обновления (изменения) внутреннего человека: ... совлекшись ветхого человека с делами его и облекшись в нового, который обновляется в ПОЗНАНИИ по образу Создавшего его (Кол. 3,9-10).

По существу это познание мира в основах его творения и вечности, который здесь мы видим внутренним человеком «как через тусклое стекло, там же лицем к лицу», как писал апостол Павел. То, что непостижимо аналитическому уму, станет понятно озаренному Христовым светом трансцендентальному сознанию внутреннего человека.

Основы такого понимания субъективного времени внутреннего человека заложил Августин Блаженный. Главные принципы бытия Бога Августин видел в Его бестелесности, бесконечности божественного начала, Его вездеприсутствии и, опирающимся на особую структуру Его времени в виде раскручивающейся спирали, вневременности и внепространственности.

Августин предлагает и первую психодинамическую модель субъективного психологического времени, которое у него состоит из трех времен или 
составляющих, находящихся в неразрывном единстве и взаимодействии. Как мы покажем ниже это полностью соответствует и нашей модели субъективного времени. По Августину это время прошедшего, время настоящего и время будущего. Здесь также можно усмотреть и аналогии с современной моделью вертикального времени профессора Хокинга.

По Августину существование трех вертикальных времен является важной основой бытия и развития личности человека. Можно говорить о трех формах этого бытия: человеке прошлого, человеке настоящего и человеке будущего. Развитие этой психологической концепции происходит опять же в XX-м, а теперь уже и XXI-м веках в понимании процесса и целей современной психотерапии.

Понятие внутреннего человека перевернуло все представление о психологии человека и психологии как науки. Субъективное историческое время своей раскручивающейся спиралью поглощает время физическое. Этот механизм и лежит в основе всего развития и формирования человеческой личности, всего человеческого познания. Человек также в процессе познания поглощает окружающий физический мир, где физические предметы превращаются сначала в объекты, а затем в абстрактные понятия, согласно психодинамическому подходу обладающими уже психоэнергетическим зарядом, формируя систему знаний, подобную объективным системам мироустройства.

Таким образом, здесь Августин Блаженный вводит важнейшие методологические принципы развития психологической мысли и психологической науки. Принцип единства личности во времени, т.е. историчности ее бытия и принцип примата личностного знания над любым другим. Именно поэтому мы и изучаем историю науки, в том числе и психологии и философии. Именно поэтому мы и говорим о вечном характере личностного знания в противовес всяким временным его моделям, например, искусственному интеллекту.

\section{СПИСОК ЛИТЕРАТУРЫ}

Лосев, А. Ф. (1993) Очерки античного символизма и мифологии. М. : Мысль.

Сочивко, Д. В. (2007) Психодинамика. М. : Изд-во МПСИ.

Дата поступления: 10.06.2019 2.

Сочивко Дмитрий Владиславович - доктор психологических наук, профессор кафедры общей психологии Академии права и управления Федеральной службы исполнения наказаний. Адрес: 390000, г. Рязань, ул. Сенная, д. 1. Тел.: +7 (903) 839-65-94. Эл. адрес: sochivo@mail.ru 
Sochivko Dmitriy Vladislavovich, Doctor of Psychology, Professor, Department of General Psychology, Academy of Law and Management, Federal Penitentiary Service. Postal address: 1, Sennaya St., Ryazan, Russian Federation, 390000. Tel.: +7 (903) 839-65-94. E-mail: sochivo@mail.ru

\section{Для цитирования:}

Сочивко Д. В. Зарождение понятий «внутренний человек» и «субъективное время» в поздней античности [Электронный ресурс] // Научные труды Московского гуманитарного университета. 2019. №4. URL: http://journals.mosgu.ru/trudy/article/view/1009 (дата обращения: дд.мм.гг.). DOI: 10.17805/trudy.2019.4.1 